\begin{tabular}{cc}
$\begin{array}{c}\text { ÇÜTAD } \\
\text { Çukurova Üniversitesi } \\
\text { Türkoloji Araştırmaları Dergisi }\end{array}$ & \multicolumn{1}{c}{$\begin{array}{c}\text { Cilt 4, Sayı 1 } \\
\text { Haziran 2019 }\end{array}$} \\
\hline $\begin{array}{l}\text { ISSN: 2587-1900 } \\
\text { E-ISSN: 2548-0979 }\end{array}$ & $\begin{array}{c}\text { Geliş Tarihi: } \mathbf{0 8 . 0 4 . 2 0 1 9} \\
\text { Kabul Tarihi: 24.05.2019 }\end{array}$ \\
$\begin{array}{l}\text { Makale Künyesi (Araştırma): Erdem, M. (2019). Türkmen Türkçesinde } \\
\text { istek eki temelinde kurulan birleşik kipler. Çukurova Üniversitesi Türkoloji } \\
\text { Araştırmaları Dergisi. } 4 \text { (1), 100-120. }\end{array}$ \\
\hline
\end{tabular}

\title{
TÜRKMEN TÜRKÇESINDE İSTEK EKİ TEMELİNDE KURULAN KATMERLİ BİRLEŞİK KİPLER
}

\section{ÖZET}

Melek ERDEM ${ }^{1}$

Türkmen Türkçesinde istek (arzu) kipinde birçok yap1 kullanılmasına karşın temelde doğrudan doğruya istek anlatan ek, Eski Türkçedeki [-gay, -gey] ekinden geliştiği düşünülen [-a, -e] ekidir. Diğer yandan bugün birleşik görünüm sergileyen [-ayad1, -eyedi] yapısı da Türkmen Türkçesinde istek anlatmak üzere kullanılan bir başka yapıdır. Türkmen Türkçesinde istek eki temelinde kurulan katmerli yapılar oldukça fazladır.

Anahtar kelimeler: Türkmen Türkçesi, Dil bilgisi, Kip, İsteme Kipi, İstek (Arzu) Kipi.

\section{DOUBLE COMPOUND VERBS AS OPTATIVE MOOD IN TURKMEN TURKISH}

\begin{abstract}
Although in Turkmen Turkish many structures are used in optative mood, [-a,-e] suffix which is thought to have developed from [-gay,-gey] suffix from old Turkish, is the suffix that expresses a wish directly in principle. On the other hand also [-ayad1, -eyedi] structure which has a compound look, is basically the structure that is used for expressing wishes directly in Turkmen Turkish. Compound mood which has been constructed based on optative mood affix are quite much in Turkmen Turkish.
\end{abstract}

Key words: Turkmen Turkish, Grammar, Mood, Subjunctive mood, Optative mood.

\footnotetext{
${ }^{1}$ Ankara Üniversitesi, Prof. Dr. merdem@ankara.edu.tr https://orcid.org/0000-0003-4273-7951
} 


\begin{tabular}{cr} 
ÇÜTAD & Türkmen Türkçesinde İstek Eki Temelinde \\
Haziran 2019 & Kurulan Birleşik Kipler \\
\hline
\end{tabular}

\section{GíRiș}

Fiillerde dile getirilen olayla ilgili anlatım yapıları olan kipler, genellikle "bildirme" ve "isteme" kipleri olmak üzere ikiye ayrılmış olarak incelenir. Fiillerin zaman bildiren bütün çekimleri bildirme kipleri içinde toplanır. Türkmen gramerlerinde habarlık kategoriyası olarak adlandırılan bildirme kipleri isimlerde ve birleşik kiplerde $i$ fiili yardımı ile kurulur. Bunlar da $i$ - fiilinin hikâye, rivayet ve şart çekimleri ile ortaya çıkar. İsteme (tasarlama) kipleri ise fiilin anlattığı kavramı belirtirken dilek, istek (arzu), gereklilik, emir kavramları taşıdıkları için, buna göre bölümlere ayrılır. Bu kiplerde ise zaman ifadesi yoktur (Ergin, 2013, s. 289; Atabay vd. 1983, s. 239-246).

Tarihsel Oğuz Türkçesinde geniş bir fonksiyonla kullanılan istek ekinin Türkmen standart türündeki kullanımlarının doğru bir tasnifinin yapılabilmesi için Türkmen dil mantığında zaten mevcut olan hikâye, rivayet ve şart ayırımlarının Türkmen gramerlerinde de oturtulması gerekir.

\section{İsteme Kipleri}

İsteme kipleri veya tasarlama kipleri Türkmen gramerlerinde forma veya şekil olarak adlandırılmakta ve emir, şart, istek, gereklilik ve niyet türleri ayırt edilmektedir. Hocayev'in Häzirki Zaman Türkmen Dilinde Isşlik Formaları (1978) adlı çalışmasında ve Söyegov'un başkanlığında hazırlanan Türkmen Diliniñ Grammatikası: Morfologiya (2000) adlı kapsamlı çalışmada şert (gelsem), şert-arzuv (yazsamdım), arzuv (geläyedim), buyruk, hökmanlık (yazmalı) ve hıyal (yazmakçı) şekilleri ayırt edilmiştir. Ancak, A. Esenmedova'nın çalışmasında hem bildirme kipleri hem de tasarlama kipleri ve fiilimsiler şekil olarak nitelenmiş ve birlikte ele alınmıştır (2010, s. 260).

\section{1. İstek Kipi}

İstek kipi isteme yani tasarlama kiplerindendir. Tasarlanan hareketin istendiğini gösterir. Ergin, isteme kipliğindeki işaretleyicinin eski Türkçedeki gelecek zaman eki [-gay, -gey]'den gelişen [-ga, -ge] şeklinden geldiğini ve Batı Türkçesinde [-a, -e] şeklini aldığını belirtmiştir. Gelecek zamanda da yer yer bir istek ifadesi görülebilir. Eski Anadolu Türkçesinde bolay kim, bolayki 'ola ki, olur ki, belki' örneğinde eski [-gay, -gey] şeklinin devamı görülür. Ergin, [-ay, -ey] şeklinin istek ifadesi taşıdı̆̆ını, zamanla emir birinci şahıs eklerinin Osmanlıca ve Türkiye Türkçesinde istek birinci şahısları için de kullanılmaya başlandığını ve bu şekilde emir ve istek şekillerinin karıştığını belirtmiştir (Ergin, 2013, s. 310-311). [-gay, -gey], [-ay, - 
ey], [-ga, -ge], [-a, -e] eklerinin eski Türkçeden beri, gereklilik-dilek, gelecek (geniş, şimdiki) zaman bildirme fonksiyonlarını devam ettirdiği bilinmektedir (Mansuroğlu, 1958, s. 183).

Birçok Türkmen dilcisi [-a, -ä, -e] ekinin, Oğuz grubu Türk lehçelerinin hepsinde kullanıldığını ve anlam olarak arzu, istek anlatarak fiilin istek kipini oluşturduğunu (Azimov, Hocayev, Sopıyev, Söyegov) belirtmişlerdir. Türkmen Türkçesinde elbette istek kipliğini ifade eden aslında birden fazla yapı vardır. İstek kipi, [-a, -e], [-adı, -edi] ve [-ayadı, -äyedi] ekleri ile anlatılmakla birlikte, [-gay, gey], [-sa, -se], [-makçı, -mekçi] eklerinin de bu anlamı vermek maksadıyla ikincil olarak kullanılabildiği görülmektedir. Ancak, [-a, e] istek ifade eden asıl ektir. Borcakov ve Hocayev çalışmalarında, J. Dény, V. Kotviç, G. İ. Ramstedt, N. A. Baskakov, E. A. Grunina, A. Annanurov, M. Ergin ve daha birçok dilcinin görüşlerine de yer vererek bu ekin, -gay, -gey > -ay, -ey > -a, -e şeklinde gelişme gösterdiğini (1980, s. 7-30) ve [-gay, -gey] ekinin fiilin arzu, istek kipini anlattığını belirtmişlerdir (Borcakov, Hocayev, 1980, s. 15; Hocayev, 1978, s. 99).

P. Azimov, M. N. Hidırov, G. Sopıyev'in redaktörlügünde ve C. Amansarıyev, G. Sarıev ve A. Ibrayımov'un da katılımlarıyla Häzirki Zaman Türkmen Dili adlı gramer çalışmasında bu kip isleg forması olarak adlandırılmış ve çekim şu şekilde verilerek çekim eklerinin emir ekleri ile benzer olmasına rağmen, bunu emir kipinden ayıran unsurun içerik ile birlikte fiil kökünün sonundaki ünlünün uzun söylenmesi olduğu belirtilmiştir (Azimov vd. 1960, s. 390-392):

1.t.k. yazayın geleyin oka:yın sözlä:yin

2.t.k. yaza: veya yaza:y

3.ç.k. yaza:sın veya yaza:ysın

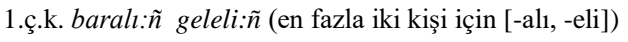

2.ç.k. yaza:ñ veya yaza:yıñ

3.ç.k. yaza:sınlar veya yaza:ysınlar

$\mathrm{Bu}$ çalışmada, bundan başka, [-ayayın, -äyeyin] eki ile de çekimine rastlandığ 1 ve bu şekilde, bir işin yapılmasının gerçekten kararlılıkla istendiğinin anlatıldığı ifade edilerek alayayın, geläyeyin,

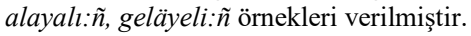

Baskakov, Hamzayev ve Çarıyarov'un birlikte hazırladıkları Grammatika Turkmenskogo Yazıa: Fonetika i Morfologiya adlı 
çalışmada, istek çekimi [-ayadı, -äyedi ] ekiyle (1970, s. 298) verilmiştir:

$$
\begin{aligned}
& \text { yaz-ayadl-m gel-äyedi-m } \\
& \text { yaz-ayadt-ñ gel-äyedi-ñ } \\
& \text { yaz-ayadı gel-äyedi } \\
& \text { yaz-ayadt-k gel-äyedi-k } \\
& \text { yaz-ayadı-ñız gel-äyedi-ñiz } \\
& \text { yaz-ayadl-lar gel-äyedi-ler }
\end{aligned}
$$

Amansarıyev, aynı yıl yayımlanan Türkmen Diyalektologiyası adlı çalışmasında bu kipi isleg forması şeklinde adlandırmış ve standart türde ve ağızların çoğunda şu şekilde bir çekimin olduğunu belirtmiştir (1970, s. 355):

1.t.k. alayın ı:zla:yın gözlä:yin

2.t.k. alasiñ gelesiñ;

1.ç.k. alalı l:zla:lı gözlä:li (iki kişi için)

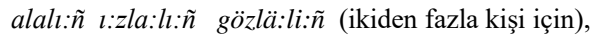

2.ç.k. alasıñı gelesiñiz

R. Berdiyev, S. Kürenov, K. Şamıradov ve S. Arazkulıyev'in hazırladıkları Türkmen Dialektleriniñ Oçerki adlı çalışmada islegbuyruk forması adı altında standart türdeki ve Teke ağzındaki çekim benzer olarak şu şekilde verilmiştir (1970, s. 316):

$$
\begin{aligned}
& \text { 1.t.k. yazayın } \quad i: \text { şlä:yin } \\
& \text { 2.t.k. yaza:y i:şlä:y } \\
& \text { 3.t.k. yaza:ysın } \quad \text { i:şlä:ysin } \\
& \text { 1.ç.k. yazalı: } \tilde{n} \quad \text { i:şlä:liñ } \\
& \text { 2.ç.k. yaza:yıñ } \quad \text { i:şlä:yiñ } \\
& \text { 3.ç.k. yaza:ysınlar i:şlä:ysinler }
\end{aligned}
$$

B. Hocayev, Häzirki Zaman Türkmen Dilinde İşlik Formaları adlı çalışmasında standart türde [-a, -e], [-adı, -edi] ve [-ayadı, -äyedi] eklerinin kullanılarak arzu, istek anlatıldığını, ancak [-adı, -edi] ve [ayadı, -äyedi] gibi birleşik yapıların birleşiminde -gay, -gey ekinden 
gelişen [-a, -e] istek kip ekinin kullanıldığını, [-ayadı, -äyedi] ekinin ay + -adı, -äy + -edi şeklinden geliştiğini belirterek çekimi; yaz-ayadl$m$, gel-äyedi-m, yaz-ayadı-ñ, gel-äyedi-ñ, yaz-ayadı, gel-äyedi, yazayadl-k, gel-äyedi-k, yaz-ayadl-ñz, gel-äyedi-ñiz, yaz-ayadl-lar, geläyedi-ler şeklinde vermiştir. Hocayev'in verdiği açıklama ve örnekler aslında bu çekimin isteğin hikâyesi sayılması gerektiğini düşündürmektedir (1978, s. 94-95). Hocayev'in verdiği örneklerdeki durum, istek şeklinde tasarlanan, fakat geçmişte gerçekleşmemiş bir olayın, gelecek zamanda gerçekleşebileceğine gönderme yapılarak anlatılmasıdır. $\mathrm{Bu}$ yüzdendir ki ekin bileşiminde [-di] işaretleyicisi bulunmaktadır. Grunina, da [-ayadi] ekindeki [-di] unsurunun geçmişe ait olduğundan dolayı istek şeklinin artık gerçekleşmeyen bir eylemi ifade ederek bir teessüfe dönüştüğünü belirtmiștir (Grunina, 2007, s. 683). ${ }^{2}$

Borcakov ve Hocayev'in birlikte hazırladıkları Türki Dilleriñ Günorta-Günbatar Toparında Arzuv ve Hökmanlık Añladyan İşlik Formaları adlı çalışmada da bu ekin \{-A idi\} şeklinden gelişmiş olduğu ve içinde bir zaman kavramı taşıdığı belirtilmiştir (1980, s. 6064, 71). Borcakov ve Hocayev çalışmalarında Türkmen Türkçesinin standart türünde istek kipinde kullanılan [-ayadı, -äyedi] ekinin gramatik anlamını $\{-\mathrm{A}\}$ ekinin anlamı ile karşılaştırarak $\{-\mathrm{A}\}$ ekinin gerçek yani olması mümkün olan arzu anlattığını ve [-ayadı, -äyedi] ekinin ise gerçekleşmemiş yani yapılmamış veya gerçekleştirilmesi mümkün olmayan istek, arzu bildirdiğini belirtmişlerdir (1980, s. 66). Nitekim bu çalışmada [-ayadı, -äyedi] ekinin konuşma esnasından önceki bir zaman dilimi ile ilgili bir isteği de anlatabileceği, ancak bu durumda konuşma anından önce olan harekette bir şeyin yapılmasına olan isteği pişmanlıkla bildirdiği ve bu sebeple, gramatik zaman anlamının ancak metnin bütününden anlaşılacağı da belirtilmektedir (1980, s. 69).

Berdiyev'in Türkmen Diliniñ Diyalektlerinde ve Gepleşiklerinde İşlikler adlı çalışmasında kip isleg forması olarak adlandırılmış ve standart türdeki ve Teke ağzındaki çekimi; yazayın, i:şlä:yin, yaza:y, i:şlä:y, yaza:ysın, i:şlä:ysin, yazalı:ñ, i:şlä:liñ, yaza:yiñ, i:şlä:yiñ,

2 Grunina, diğer yandan [-ayadı, äyedi] ekini Batı Sibirya'daki Tatar ağızlarındaki [-adı, -edi] ekli şimdiki zaman ile karşılaştırarak Türkmen Türkçesinde görülen çekimin [-ad1] ekli çekim ile aynı olduğunu dile getirmiştir (2007, s. 683). Ancak Tatar ağızlarındaki bu şimdiki zaman yapısının yine Çovdur, Surhı, Çandır, Düyeçi gibi birçok Türkmen ağzında görülen ve [-a + turur] yapısından gelişen bir [-adır, -adı] şimdiki zaman eki ile bağlantısı olabilir (Erdem 2000). Daha çok şimdiki veya geniş zamana gönderme yapan [-ad1, -edi] eki, gramer ve fonksiyon bakımından [-ayadı, äyedi] eki ile karıştırılmamalıdır. 
yaza:ysınlar, i:şlä:ysinler şeklinde basit (çılşııımsız / yönekey) çekimi ile verilmiştir (1988: 238). Grunina, Türkmen Türkçesindeki bu durumu, daha çok konuşanın ifade ettiği istekle ilgili düşüncesini bildirme olan optativ terimi ile tanımlamış ve bu şekillerin fonksiyon alanı geniş, ettirgenlik unsurunu içine almayan, arzu, dilek, temenni, uyarma gibi anlamları ifade ettiğini ve Türkmen gramerlerinde ekin gösterilmekle birlikte, gramer niteliğinin yeterince tanımlanmadığını belirterek [-a], [-ay] ve [-aya] eklerinin bir modus morfemi olduğunu söylemiştir (2007, s. 682).

Azimov, Sopıyev, Çöññäyev'in birlikte hazırladıkları Türkmen Dili adlı kitapta, istek kipi işliğiñ buyruk forması başlığı altında değerlendirilmiş ve [-ay, -äy] ekinden söz edilirken "işliğiñ buyruk forması"nın yumuşatılan istek, dilek görünüşünü yaptı̆̆ 1 belirtilerek çekimi şu şekilde vermişlerdir (1992, s. 230-231):

Men yazayayın işläyeyin

Sen yazay işläy

Ol yazaysin işläysin

Biz yazayalı̃ işläyeliñ

Siz yazayıñ işläyiñ

Olar yazaysınlar işläysinler

M. Söyegov'un genel redaktörlügünde ve A. Borcakov, M. Sarıhanov, M. Söyegov, B. Hocayev ve S. Ärnazarov'un katkılarıyla hazırlanan Türkmen Diliniñ Grammatikası: Morfologiya adlı kapsamlı çalışmada [-ayadı, -äyedi] ekiyle kurulu çekim verilmiş ve [ayadı, -äyedi] ekinin yapısında [-ay, -äy] ve [-adı, -edi] eklerinin bulunduğu, [-adı, -edi] şeklinin bugün Türkmen standart türünde kullanımının oldukça sınırlı olduğu, anlam olarak [-ayadı, -äyedi] ekinden ayırt edilmediği, [-a, -e] ekinin ikinci ve üçüncü şahıs çekimlerinde kullanımının sınırlı olduğu belirtilmiştir (Söyegov vd. 2000, s. 291).

M. Söyegov ve S. Arnazarov'un birlikte hazırladıkları Örnekli Türkmence Gramer (2017) adlı çalışmada (2017, s. 73) ise [-ayadı, äyedi] eki ile kurulu çekim istek kipi için esas alınmıştır.

Ancak, bütün Oğuz Türkçelerinde olduğu gibi Türkmen Türkçesinde de kararlı bir şekilde arzu, istek anlatan ekin [-a, -e] olduğu, konuşma diline yansıyan görünüşlerden de anlaşılmaktadır. Eklerin, aslî fonksiyonları olabildiği gibi ikincil fonksiyonlarda kullanımları da olabilmektedir. İstek kipliğinin asıl işaretleyicisi, 
bütün tarihsel ve modern Oğuz Türkçelerinde olduğu gibi Türkmen Türkçesinde de [-a, -ä, -e] veya [-ay, -äy, -ey] ekidir. Bu sebeple adlandırmanın da bu temel fonksiyonlar üzerinden yapılması gerekmektedir.

Grammatika Turkmenskogo Yazıka I: Fonetika i Morfologiya (1970) adlı çalışma ile başlayan [-ayadı, -äyedi] ekinin doğrudan istek eki olarak kabul edilmesi geleneği günümüze kadar gelmiş, ancak aynı dönemlerde Türkmen Dialektleriniñ Oçerki (1970) ve Türkmen Diliniñ Diyalektlerinde ve Gepleşiklerinde İşlikler (1988) adlı çalışmalarda standart tür için gösterilen ve doğru olan istek çekimi (1988, s. 238) göz ardı edilmiştir.

Günümüzde Türkmen Türkçesinin standart türünde [-a:yadı, ä:yedi] şekli istek, arzu anlatımında kullanılsa bile bu yapının, fonksiyonel ve gramatikal açıdan bir şekilde geçmişteki bir durumu da anlatmasından dolayı "isteğin hikâyesi" olarak değerlendirilmesi gerekmektedir. Nitekim, Borcakov ve Hocayev de çalışmalarında [ayad1] ekinde gerçekleşmemiş veya gerçekleştirilmesi mümkün olmayan istek anlatıldığını belirtirken aslında, ekin geçmiş zamanda gerçekleşmemiş bir olaya da gönderme yaptığına işaret etmektedirler. Konu tarihsel olarak düşünüldüğünde ve Türkmen Türkçesindeki yazılı ve sözlü kullanımlar değerlendirildiğinde, [-ay, -ey] veya [-a, -e] ekinin doğrudan istek kipliğini kuran asıl işaretleyici olarak kabul edilmesi gerekmektedir.

Emir ve istek çekimlerinde teklik ve çokluk birinci kişiler karışabilmektedir. Ancak buna rağmen eşzamanlı bakış açısıyla, Türkmen Türkçesinde, kullanımda, emir ve istek çekimlerinin aslında morfolojik olarak da ayırt edilebildiği görülmektedir. Bu sebeple istek çekiminin bütün kullanımları göz önüne alındığında, emir ve istek çekimlerinin Türkmen gramerlerinde mutlaka ayrı ayrı başlıklar altında yer alması gerektiği anlaşılmaktadır:

\begin{tabular}{|c|c|c|c|}
\hline & Emir & İstek & İsteğin Hikâyesi \\
\hline 1.t.k. & yazayın, işlä:yin & $\begin{array}{l}\text { yazayın, } \\
\text { yazayayın, } \\
\text { işläyeyin }\end{array}$ & $\begin{array}{l}\text { yaza:yadım, } \\
\text { işlä:yedim }\end{array}$ \\
\hline 2.t.k. & $\begin{array}{l}\text { a) yaz, işle } \\
\text { b) yazgın, işlegin } \\
\text { c) yazsana, işlesene }\end{array}$ & $\begin{array}{l}\text { yaza:y (yaza:), } \\
\text { işlä:y }\end{array}$ & $\begin{array}{l}\text { yaza:yadiñ, } \\
\text { işlä:yediñ }\end{array}$ \\
\hline 3.t.k. & yazsın, işlesin & $\begin{array}{l}\text { yaza:ysın, } \\
\text { işlä:ysin }\end{array}$ & $\begin{array}{l}\text { yaza:yadl, } \\
\text { işlä:yedi }\end{array}$ \\
\hline 1.ç.k. & 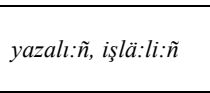 & $\begin{array}{l}\text { yazalıñ, } \\
\text { yazayalın, } \\
\text { işläyeliñ }\end{array}$ & $\begin{array}{l}\text { yaza:yadık, } \\
\text { işlä:yedik }\end{array}$ \\
\hline 2.ç.k. & a) yazın, işlä: $\tilde{n}$ & yaza:yıñ & yaza:yadiñz, \\
\hline
\end{tabular}




\begin{tabular}{|c|c|c|c|}
\hline & 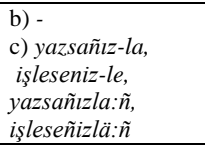 & 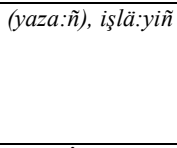 & işlä:yediñiz \\
\hline & Emir & İstek & İsteğin Hikâyesi \\
\hline 3.ç.k. & yazsınlar, işlesinler & $\begin{array}{l}\text { yaza:ysinlar } \\
\text { (yaza:sınlar), } \\
\text { işlä:ysinler }\end{array}$ & $\begin{array}{l}\text { yaza:yadilar, } \\
\text { işlä:yediler }\end{array}$ \\
\hline
\end{tabular}

Türkmen Türkçesindeki kullanımlarından standart türde teklik ve çokluk 1. kişilerde [-ayayın, -äyeyin], [-ayalıñ, -äyeliñ] eki ile yapılan çekimde, bir işin yapılmasının gerçekten daha kararlılıkla istendiği anlaşılmaktadır:

\begin{tabular}{|c|c|c|}
\hline & Emir & İstek \\
\hline \multirow{25}{*}{ 1.t.k. } & Men $\quad$ öñi & Belki, menden utanyandir, \\
\hline & kolhozçılarıñ gerekli kömege & men daş çıayayın - diyip, \\
\hline & tayınlıklarını mälim edeyin, & Seyitmırat beg daş çıkdı \\
\hline & onsoñam - astrlık arzuviñ & (Govşudov 1989: 629). 'Belki \\
\hline & yüze çıkarllyan göreşini & benden utaniyordur, ben \\
\hline & slnlayın hem saña arma & dışarı çıkayım, diyerek \\
\hline & diyeyin diyip geldim - & Seyitmırat Beg dışarı çıktı.' \\
\hline & $\overline{\text { Kerbabayev, }} \quad$ B., Suv & \\
\hline & Damcası - altın dänesi, 1973: & \\
\hline & 117 (Borcakov ve Hocayev & \\
\hline & 1980: 43). 'Ben öncelikle & \\
\hline & çiftçilerin gereken yardıma & \\
\hline & hazır olduklarını bildireyim, & \\
\hline & ondan sonra asırlik arzunun & \\
\hline & meydana çıkarılan & \\
\hline & mücadelesini seyredeyim ve & \\
\hline & sana kolay gelsin diyeyim & \\
\hline & diye geldim.' & \\
\hline & Gara batır, men hödür- & \\
\hline & keremi-de unudupdırın. Öye & \\
\hline & girelin, nahar tayyarladayın & \\
\hline & (Govşudov 1989: 236). & \\
\hline & 'Gara Batır, ben izzet ikramı & \\
\hline & da unutuvermişim. Eve & \\
\hline & $\begin{array}{l}\text { girelim, } \\
\text { hazırlatayım.' }\end{array}$ & \\
\hline \multirow{3}{*}{ 2.t.k. } & $\begin{array}{l}\frac{\dot{I} \text { sle cenayat bil, } \underline{\text { isle cenayat }}}{\text { däl (Hudaynazarov 1970). }} \\
\text { 'İster suc bil, ister bilme.' }\end{array}$ & $\begin{array}{l}\text {-Vah köşek, seni görse yene } \\
\text { beterlär. Sen birki günden soñ } \\
\text { aöräy! } \text { (S. Taŏanov } 1992 \cdot\end{array}$ \\
\hline & & $\begin{array}{l}\text { goray! (Ş. Iaganov 1992: 44) } \\
\text { '-Vah yavrum, seni görse yine }\end{array}$ \\
\hline & & $\begin{array}{l}\text { kötüleşir. Sen bir iki gün } \\
\text { sonra gör.!' }\end{array}$ \\
\hline
\end{tabular}




\begin{tabular}{|c|c|c|}
\hline & $\begin{array}{ll}\text { Hökman } & \text { turuzgln } \\
\text { (Hudaynazarov } & 1970 \text { ). } \\
\text { 'Mutlaka kalk.' } & \end{array}$ & 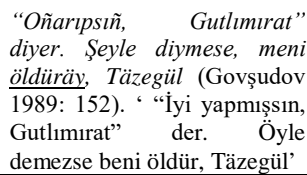 \\
\hline & Emir & İstek \\
\hline 3.t.k. & $\begin{array}{l}\text { Onda başlığa aydiñ-da tay } \\
\text { bersin bize (Hudaynazarov } \\
\text { 1970: } 25 \text { ). 'O zaman başkana } \\
\text { söyleyin de at versin bize.' }\end{array}$ & $\begin{array}{l}\text { Indi namazı herkim öz öyünde } \\
\text { okaysın-diyip, yanindakl üç } \\
\text { lhlasgärine hem ruğsat berdi } \\
\text { (Govşudov 1989: 25). 'Şimdi } \\
\text { namazı herkes kendi evinde } \\
\text { k1lsın, diyerek, yanındaki üç } \\
\text { müridine de izin verdi.' }\end{array}$ \\
\hline 1.ç.k. & $\begin{array}{l}\text { Hanı düsünisseli, o nähili } \\
\text { etsem-petsem? } \\
\text { (Hudaynazarov 1970: 120). } \\
\text { 'Hadi anlaşalım, o nasıl } \\
\text { yapsam mapsam?' } \\
\text { Geliñ bizem islese bu yigidi } \\
\text { öz aramızda saklalıñ } \\
\text { (Tağanov 1992: 72). 'Gelin } \\
\text { bizi de isterse bu yiğidi kendi } \\
\text { aramızda saklayalım.' }\end{array}$ & $\begin{array}{l}\text { Niyazmırat aganiñ duşuşan } \\
\text { yll diyip alayalıñ (Govşudov } \\
\text { 1989: 942). 'Niyazmirat } \\
\text { Ağanın denk geldiği y1l diye } \\
\text { alalım.' }\end{array}$ \\
\hline 2.ç.k. & $\begin{array}{l}\text { Gayrat ediñ (Hudaynazarov } \\
\text { 1970: 25). 'Gayret edin.' }\end{array}$ & $\begin{array}{l}\text { Men gözzüm üstüne barardim } \\
\text { velin, häzir mihmanım bar. } \\
\text { Siz pattşa şey diyip aydayıñ, } \\
\text { diyen. -Dana Goca- } \\
\text { (Halmuhammedov 1981: 107) } \\
\text { 'Ben bašüstüne giderdim } \\
\text { fakat, şimdi misafirim var. Siz } \\
\text { padişaha öyle söyleyin, } \\
\text { demiş.' }\end{array}$ \\
\hline
\end{tabular}

Bu örneklerde görüldüğü üzere teklik ve çokluk 1. kişilerde emir ve istek kullanımları anlam ve fonksiyon olarak birbirlerinin yerini alabilmektedirler. Ancak çıkayayın şeklinde daha kararlı bir istek anlatımı dikkati çekmektedir. Teklik 2. kişide, emir ve istek çekimleri hem morfolojik açıdan hem de fonksiyonel ve semantik açıdan ayırt edilebilmektedir. Çokluk 2. ve teklik 3. kişilerde de [-ay, -äy] ekinin kullanımı ile (emir kipindeki kulanıma göre) daha güçlü bir istek ifade edilmiştir.

\section{Birleşik Kipler}

Türkmen gramerlerinde birleşik kip konusu öten zaman ve gelcek zaman konuları içerisinde çılşırımlı formalar adı altında değerlendirilmektedir. 
Gacarova, 18. -19. asır eserlerinde çılşırımlı öten zamanın; [-ur, ür, -1r, -ir, -ar, -er] ekleri üzerine erdi getirilerek kurulan ve [-mış, miş / -1b, -ib / -an, -en (< -gan, -gen)] ekleri üzerine erdi getirilerk kurulan, olmak üzere iki görünüşü olduğunu belirtmiştir (Çarıyarov, 1969, s. 169-170).

B. Çarıyarov, 1969'da hazırladığı Günorta-Günbatar Türki Dillerde Isşlik Zamanları adlı önemli çalışmasında çılşııımlı öten zaman adıyla hangi yapıların buna dahil edilmesi gerektiği, sayıları, her birini nasıl adlandırmak gerektiği gibi meselelerde bir birlik sağlanamadığını belirtmiştir (1969, s. 167-168). Öten zamanıñ çılşırımlı formalarının çoğu Sovyet dönemi öncesi çalışmalarda da gösterilmiştir. Mesela, P. Şimkeviç [-ıpdır] yapısını çılşırımlı formalar içinde değerlendirmiştir. İ. A. Belyayev ise; yazardım, yazardıñ, ... (Прошедшее несовершенное), yazar imişim, yazarmışım (прошедшее повествовательное), yazar eken-men, yazar eken-sen (прошедшее повествовательное (достоверное)), yazlp dur (прошедшее время 3-го лица), yazıp-dim, yazlp-diñ (давнопрошедшее) yapılarını birleşik yapılar içinde değerlendirmiştir. A. Ş. Garahanov, bu karmaşı yapıları (прошедшеe время несовершенного вида); 1) al-ya- $\left.d_{l}-m, 2\right)$ al-cak-dl-m, 3) al-ardl-m, 4) al-mall-dl-m, 5) al-makçl-dl-m, 6) al-ıp-dl-m, 7) al-ıp-dır-ın, 8) al-ıp-mış-ım, 9) al-ıp-dır-mış-ım, 10) al-an-dır-ın, 11) al-an-mış$\imath m$, 12) al-an eken-im, 13) al-sa-m-dl-m olmak üzere 13 gruba ayırmıştır (Çarıyarov, 1969, s. 167-168).

Häzirki Zaman Türkmen Dili adlı çalışmada bu karmaşık yapılar, habarlık kategoriyasını̃̃ kömeği bilen yasalyan öten zaman formaları (bildirme kategorisi yardımı ile yapılan geçmiş zaman şekilleri) adı altında verilmiştir. Burada şu yapılardan söz edilmiştir: 1) [-yar-d1] (alyardl), 2) [-ar-d1] (alardlk), 3) [-sa ... -ard1] (aydan bolsañ ... giderdim), 4) [-cak-d1] (okacakdım), 5) [-mal1-d1] (açmalıdım), 6) [-makçı-d1] (yazmakçıdım), 7) [-ıp-dı] (gelipdik), 8) [an-d1] (işländi, görendi), 9) [-sa-d1] (alsadım, girsedi), 10) [-yan-d1] (saklayandı), 11) [-an-mış] (değenmiş), 12) [-1p-mış] (alıpmış), 13) [an-dır] (gelendir), 14) [-ıp-dır] (alıpdır), 15) [-an eken] (alan eken), 16) [-ar eken] (alar eken), 17) [-malı eken] (gitmeli eken) (Azimov vd. 1960, s. 377-382; Çarıyarov, 1969, s. 168-169).

Çarıyarov, öten zamanıñ çılşırımlı formalarını, basit zamanların arkasından kem işliklerin yani $i$ - fiilinin şahsa göre çekimlerinin getirilerek yapıldığını belirterek; 1. Mälim dovamlı öten zaman, 2. Nämälim dovamlı öten zaman, 3. Gelcek öten zaman, 4. Öñki öten zaman olmak üzere dört türünü belirlemiştir (Çarıyarov, 1969, s. 276). 
Türkmen Diliniñ Grammatikası: Morfologiya adlı çalışmada Türkmen Türkçesinde [-d1, -di], [-dır, -dir], [-mış, -miş], [-ka, -kä] ekleri ile eken sözünden meydana gelen kem işliklerin habarlık kategoriyası veya habarlık affiksleri olarak adlandırılışının yaygın olduğu dile getirilmiş ve [-yardı, -yärdi] yapısı mälim dovamlı öten zaman, [-ardı, -erdi] yapısı nämälim dovamlı öten zaman, [-cakdı, cekdi] yapısı hryal-meyil öten zaman, [-1pd1, -ipdi, -upd1, -üpdi] yapısı öñki öten zaman olarak işliğiñ öten zamanı başlığı altında alınmış ve diğer yandan kem işliğiñ $-d l$, -di goşulması başlığı altında da değerlendirmişdir (Söyegov vd. 2000, s. 251-264, 361-364, 372-374).

Söyegov ve Arnazarov'un birlikte hazırladıkları Örnekli Türkmence Gramerde (2017) ise birleşik kipli fiillerin; 1. belirli devamlı geçmiş zaman ([-yardı, -yärdi]), 2. belirsiz devamlı geçmiş zaman ([-ard1]), 3. Niyet bildiren geçmiş zaman ([-cakd1]) 4. Şimdiki zamanın rivayeti ([-yarmış]) 5. Gelecek zamanın rivayeti ([-cakmış]) olmak üzere 5 çeşit olduğu belirtilmiştir (Söyegov ve Arnazarov, 2017, s. 76-78).

Ancak, Türkmen Türkçesinde $i$ - fiilinin [-d1, -di] çekimi ile hikâye, $\{$-mIş\} çekimi ve ayrıca eski Türkçe $e r$ - fiilinden gelişen eken sözü ile rivayet ve [-sa] eki ve ayrıca bol- yardımcı fiili ile de kurulabilen şart çekimi vardır. Geniş, şimdiki, gelecek ve belirsiz geçmiş zaman ekleri üzerine gelerek $\{-\mathrm{Ar}\}+\{-\mathrm{mIş}\} ;\{-\mathrm{yAr}\}+\{-$ $\mathrm{mIS}\} ;\{-\mathrm{An}\}+\{$-mIş $\} ;\{-\mathrm{Ip}\}+\{-\mathrm{mIş}\} ;\{-\mathrm{cAk}\}+\{-\mathrm{mIS}\} ;\{-\mathrm{mAlI}\}+$ $\{-\mathrm{mIş}\}$ yapıları ile kurulan rivayet çekimi aracılığıyla, konuşurun olumsuz bakış açısı, isteksizliği, ya da imada bulunuşu veya kinaye veya bir alay anlatması da sağlanır ve konuşurun anlattığg düşünceyi kendi gözüyle görmediğini, başkasından duyduğunu ve bununla birlikte doğruluğuna, kesinliğine şüphe duyduğunu veya tahmin ettiğini ifade eder. Türkmen Türkçesinde eken sözü ile yapılan rivayet çekimi ile [-mış, -miş] yapısı arasında hiç bir anlam ve fonksiyon farkı olmadığı kullanımdan anlaşılmaktadır. Türkmen Türkçesinde şart çekimi genelde $i$ - fiilinin yüzey yapıdaki görünüşlerinden biri olan bol- yardımcı fiili aracılığıyla perifrastik olarak ortaya çıkar. Ancak isteğin şartında, şart eki doğrudan istek eki üzerine gelebilmektedir.

$\mathrm{Bu}$ durumda, Türkmen Türkçesinde şu birleşik kiplerin kullanıldığı gözlemlenmektedir:

1. Nämälim öten zamanıñ hekayası ([-1pdi]]),

2. Häzirki zamaniñ hekayası ([-yardı]),

3. Nämälim gelcek zamanıñ hekayası ([-ard1]),

4. Mälim gelcek zamanıñ hekayası ([-cakd1]), 
5. Arzuvuñ hekayası ([-ayad1]),

6. Şertiñ hekayası ([-sadi] ),

7. Hökmanlığıñ hekayası ([-malıdı]),

8. Hiyal şekiliniñ hekayası ([-makçıdı]),

9. Nämälim öten zamanıñ rovayatı ([-1pmış]),

10. Häzirki zamanıñ rovayatı ([-yarmış] veya [-yar eken]),

11. Nämälim gelcek zamaniñ rovayatı ([-armış]),

12. Mälim gelcek zamanıñ rovayatı ([-cakmış] veya [-cak eken]),

13. Arzuvuñ rovayatı ([-aymış]),

14. Hökmanlığıñ rovayatı ([-malımış] veya [-malı eken]),

15. Hıyal şekiliniñ rovayatı ([-makçımış] veya [-makçı eken]),

16. Nämälim öten zamanı̃ şerti $(\{-\mathrm{Ip}\}+$ bolsa; $\{$-mA:n $\}+$ bolsa, $\{$-An $\}+$ bolsa; $\{$-mAdIk $\}+$ bolsa, $\{$-yAn $\}+$ bolsa $)$,

17. Häzirki zamanıñ şerti $(\{-\mathrm{yAr}\}+$ bolsa $)$,

18. Nämälim gelcek zamanıñ şerti $(\{-\mathrm{Ar}\}+$ bolsa $)$, bolsa),

19. Mälim gelcek zamaniñ şerti $(\{$-cAk $\}+$ bolsa; $\{$-mAcAk $\}+$

20. Arzuvuñ şerti ([-aysa]),

21. Hökmanlı̆̆ıñ şerti $(\{-\mathrm{mAlI}\}+$ bolsa $)$,

22. Hiyal şekiliniñ şerti $(\{-\mathrm{mAkçI}\}+$ bolsa $)$

\section{1. İstek Kipinin Hikâyesi}

Türkmen standart türünde [-a:yadı, -ä:yedi] şeklinin, fonksiyonel ve gramatikal açıdan geçmişteki bir durumu anlatmasından dolayı "isteğin hikâyesi" olarak değerlendirilmesi gerekir. [-aydı] ve [-ayadı] yapıları arasında anlam ve kullanım farkının olmadığı anlaşılmaktadır.

İstek ile isteğin hikâyesi arasındaki anlam ve kulanım farkı ise şu örneklerden rahatlıkla anlaşılmaktadır.

Teklik 1. kişi

Çay sovandır, täzeden gaynadayayın (Aşır, s. 193). 'Çay soğumuştur, yeniden kaynatayım’ (istek) 
Meniñ senden bir zat sorasım gelyä, sorayınm ? (Deryayev, s. 14). 'Benim senden bir şey isteyesim var, isteyeyim mi' (istek)

Yañkl bu gidişine rayona barı, biziñ işimizi görer. Illki onuñ ăgzına düşsenem men bolaydım- diyip, yoldaşlarını̃ geplemän oturışııdan dilgir boldı (Durdiyev, 1982, s. 96). 'Deminki bu gidişinde rayona gidip, bizim işimizi görür. Öncelikle onun diline düşen de ben olaydım, diyerek yoldaşlarının konuşmadan oturuşundan rahatsız oldu.' (isteğin hikâyesi)

Teklik 2. kişi

Sen alay. Gerek bolsa men yene ylğarın (Deryayev, s. 14). 'Sen al. Gerekirse ben yine toplarım.' (istek)

Maña geläy. Maña razı bolay (Deryayev, s. 142). 'Bana gel, beni kabul et.' (istek)

Hoş geldiñ, Stepan aga - diyip, begencini bildirdi. - Özüñ tüys vagtında geläydiñ. Şunça gelmedik bolsan, üstüñe adam ibercekdim ya-da özüm barcakdım. -Meniñ bu gün dinç alyan günüm - diyip, Stepan aga gürrüñ bermäge başladı (Govşudov, 1989, s. 553). 'Hoş geldin, Stepan Ağa, diyerek, sevincini belirtti. - Sen tam vaktinde geleydin/geldin. Bu zamana kadar gelmemiş olsan/olsaydın peşine adam gönderecektim ya da kendim gelecektim. -Benim bugün dinlenme günüm, diyerek, Stepan Ağa sohbet etmeye başladı.' (isteğin hikâyesi)

-Oglanlar, Marınam elden gideräydiñizmi? - diyip, sipayıçılık bilen söze başladı (Govşudov, 1989, s. 898). ‘-Delikanlılar, Marı’yı da (mı) elden çıkardınız mı, diyerek nazikçe söze başladı.' (isteğin hikâyesi)

\section{Teklik 3. kişi}

Gicäniñ haysı bir vagtı bolsa bolaysın, ol: "Hay, yagı çozdl, atlañ hov!” diyip, galanı örüzyär (Govşudov, 1989, s. 21). 'Gecenin hangi olursa olsun, o "Hey, düşman çöktü, atlara atlayın, hey!" diyerek diğerlerini uyarır.' (istek)

Belki siziñ tövellañız alayadı-da. Meni beydip horlamasın (Deryayev, s. 338). 'Belki sizin hayır duanızı alaydı da. Beni böyle hor görmesin.' (isteğin hikâyesi)

Belki bir oñat adam dușayadı-da. (Deryayev, s. 245). 'Belki de bir iyi insan rast geleydi.' (isteğin hikâyesi) 


\section{2. İstek Kipinin Rivayeti}

İsteğin rivayeti, [-ay, -äy] istek eki üzerine [-ıpdır], [-andır], [yandır] eki getirilerek kurulabilmektedir. Bu şekilde istek ile birlikte bir tür şart da ifade edilmiş ve [-1pdır] eki ile de hem zaman kavramı verilmiş hem de tahmine dayalı bir kesinlik ifade edilmiş olmaktadır:

Imızganan yalı edäyipdirin 'İrkilmiş gibi yapaymışım.' (Söyegov vd. 2000, s. 261).

Bä, ussa, sen-ä munı ömürlik edäyipsiñ, daşınıñ demri-dă̆ısı bile biten yalı ... (Durdıyev, 1982, s. 194). 'Peh, usta, sen de bunu ömürlük yapmışsın, dışının demiri ve sairesi bile bitmiş gibi ...'

Kellesi kesilip sırtında goylayyandır. Emma bu gürrüñçilikde gelip gep nokatlayar (Govşudov, 1989, s. 145). 'Başı kesilip sırtına koyulmuş ama bu sohbete gelip nokta koyuyor.'

\section{3. İstek Kipinin Şartı}

İstek eki üzerine şart eki getirilerek tahmin etme veya zannetme anlatılabilir. Bu anlamı daha güçlü vermek için çoğunlukla öncesinde olumsuzluk eki de getirilebilmekte (Söyegov vd. 2000, s. 283) ve bu şekilde gramatikal açıdan isteğin şartı çekimi ortaya çıkmaktadır. Ancak doğrudan şart bildirir veya memnuniyet duygusunu verebilmek için de kulanılabilir. Bu şekilde istek eki de kullanılarak yapılan şart ifadeleri Türkmen Türkçesinde sıklıkla kullanılmaktadır:

Men-ä şundan öyüme aman-sağ dolanıp baraysam, öyümizdäkiler bilen gepleşip, derrev esgerliğe gaytcak (Tağanov, 1992, s. 180). 'Ben de burdan evime sağ salim dönüp gitsem, evdekilerle konuşup, hemen askerliğe döneceğim.'

Ĕger bir yerde ă̆zıñdan sipdıraysañ, onsoñ soñ govı bolmaz. Düşünyärmiñ? (Govşudov, 1989, s. 155). 'Eğer bir yerde ağzından kaçırırsan sonu iyi olmaz. Anlıyor musun?'

Indi seni huday tutaymasa, başga tutcak yok (Govşudov, 1989, s. 77). 'Şimdi seni Allah esirgemese başka esirgeyecek yok.'

Ol gıbatçı bolaymasa. 'O dedikoducu olmasın.'

Batır, maslahat bilseñ, seni ŭgradaysak nädyär? (Govşudov, 1989, s. 279). 'Batır, tavsiye istersen, seni göndersek ne olacak,...'

Eger Gutlımırada gamçı çalaysañız, hökman gursağıñızdan pıçağı dikerin (Govşudov, 1989, s. 146). 'Eğer Gutlımırad'a kamçı vurursanız, mutlaka boğazınıza bıçağı saplarım.' 
-Hiç kimem göresi yok. Buğdayiñ içine gireli. Üstümizden geläymeseler, göresleri yok. (Hocageldiyev, 1974, s. 184). '-Hiç kimsenin de göreceği yok. Buğdayın içine girelim. Üzerimize gelmeseler, görecekleri yok.'

\section{Katmerli Birleşik Kipler}

Türkmen Türkçesinde istek eki üzerine doğrudan zaman eklerinin getirilmesi ile kurulan yapılar dikkati çeker.

\subsection{Geniş Zamandaki İstek}

İstek eki üzerine geniş zaman ekinin getirilmesiyle geniş zamanda anlatılan hareket için konuşurun isteği ifade edilmektedir:

Nika toyundan soñ gidäyersiñ. (Tağanov, 1992, s. 259). 'Nikah merasiminden sonra gidersin.'

Bir zat berseñ alman durcak gümanlarl yok. "Bayları̃̃ obasında oynap, köp pul gazanip geldik" diyip, olara-da beräyeris. İne, onsoñ alan alkışımız gazanan günämizi yuvar gider (Tağanov, 1992, s. 112). 'Bir şey versen almayacak halleri yok. "Zenginlerin obasında oynayıp, çok para kazanıp geldik” diyerek onlara da veririz. İşte, ondan sonra aldığımız dualar ettiğimiz günahı yıkar gider.'

\section{2. Şimdiki Zamandaki İstek}

İstek eki üzerine şimdiki zaman ekinin getirilmesiyle şimdiki zamanda anlatılan harekete konuşur tarafindan bir istek anlamı kat1labilmektedir:

Yetişip bilmän geçäyyän (< geçäyyärin). Beräyer yalı şu vağt kolhozlada bir arta-taşa zat yok (Hocageldiyev, 1974, s. 43). 'Yetişemeden geçiyorum. Verecek gibi (vermeye yetecek kadar) şu vakit çiftliklerde bir artan, taşan fazla bir şey yok.'

Her sapar sen öyde galaniñda, biz ir çlkayyas (çıkayyarıs). (Govşudov, 1989, s. 454). 'Her seferinde sen evde kaldığında, biz erkenden çıkıyoruz.'

\subsection{Gelecek Zamandaki İstek}

İstek eki üzerine, gelecek zaman ekinin getirilmesiyle gelecek zamanda olacağı anlatılan harekete konuşur tarafindan bir istek anlamı kat1labilmektedir:

Onda ol gıza meniñ özüm hossar çlkaycak. Yöne il meniñ kimdiğime seredip durmaz (Govşudov, 1990, s. 649). 'O zaman o kıza ben kendim arka çıkacağım. Fakat el benim kim olduğuma bakmaz.' 
Vah, beyle bolsa, adamlariñ eğninden göterilen yalı bolaycak-la (Hocageldiyev, 1974, s. 271). 'Vah, öyle olsa, insanların omuzundan kaldırılmış gibi olacak ya.'

\section{4. İsteğin Gerekliliği}

İstek eki üzerine gereklilik ekinin getirilmesiyle gereklilik kavramına konuşur tarafindan belli belirsiz bir istek anlamı katılabilmektedir:

Yaşulı, biz doğrı işanıñ huzurına barıp, yapı-yağdayımızı aydaymalımı?-diyip soradı (Tağanov, 1992, s. 22). 'İhtiyar, biz doğru hocanın huzuruna çıkıp, hal ahvalimizi anlatmalı mıyı, diye sordu.'

\subsection{Geniş Zamandaki İsteğin Hikâyesi}

Türkmen Türkçesinde istek eki üzerine olumsuz geniş zamanın hikâyesinin getirilerek geniş zamanda anlatılan bir olay ya da duruma konuşurun olumlu veya olumsuz bakış açısı vurgulanabilmektedir. $\mathrm{Bu}$ durumda ekin anlamı, yeterllik fiilinin olumsuz geniş zamanında kullanılan zarf fiil ekinin fonksiyonu ile karışabilmektedir:

Bizem onı perraçlara urduraymazdık (Govşudov, 1990, s. 147). 'Biz de onu askerlere vurduramazdık.'

\section{6. İsteğin Şartının Hikâyesi}

Türkmen Türkçesinde istek eki üzerine şartın hikâyesi getirilerek, geçmiş zamanda yapılmamış ama yapılması gereken bir hareket, konuşurun isteği de katılarak anlatılabilmektedir:

Äkidiñ, äkidiñ, käsgä, eneñizem okuva alıp gidäyseñizdiñiz!-diydi (Durdıyev, 1982, s. 157). 'Götürün, götürün, keşke, annenizi de okula alıp gitseydiniz.'

Tizräk geläysedi. Menem bir öy bolaysadım, seni ayamda saklardım-diyip, Sabır selkini bağrına basdı (Tağanov, 1992, s. 192). 'Çabucak gelseydi. Ben de bir ev olsaydım, seni içimde saklardım, deyip Sabır Selki'yi bağrına bastı.'

Bu örneklerde gidäyseñizdiñiz, geläysedi, bolaysadım sözlerinde geçmiş zamanda yapılması istenen bir hareket yarım kalmış bir şarta bağlanarak anlatılmıştır.

\section{7. İsteğin Rivayetinin Rivayeti}

Türkmen Türkçesinde istek eki üzerine belirsiz geçmiş zamanın rivayeti getirilerek kurulan yapılar geçmiş zamandaki bir isteğe gönderme yapar: 
Yağşı, şu kapitan Vepa diyilyän seniñ oğluñ bolayıpmıșınmı?diydi (Govşudov, 1990, s. 201). 'Peki, şu yüzbaşı Vepa denilen (kişi) senin oğlun oluyor muymuş (oğlun muymuş)?'

$\mathrm{Bu}$ örnekte bolayıpmışın sözünde geçmiş zamanda olmuş fakat bilinmeyen fakat öğrenilmesinde olumlu bir yaklaşım hissedilen bir durum anlatılmıştır.

\section{8. İsteğin Gerekliliğinin Rivayeti}

Türkmen Türkçesinde istek eki üzerine gerekliliğin rivayeti getirilerek geçmiş zamanda gerçekleşmeyen fakat gerçekleşmesi gerekli olan bir harekete konuşurun isteği de katılabilmektedir:

Yok, eğer bar-a, şu hakıkatmış, şoña hakıkat ınanaymalımıș (Govşudov, 1990, s. 860). 'Yok, eğer, var ya, o gerçekmiş, ona gerçekten inanmak lazımmış.'

\section{9. İsteğin Niyet Kipinin Şartı}

Türkmen Türkçesinde istek eki üzerine niyet eki getirilerek ve şart eki almış bol- yardımcı fiili vasıtasıyla perifrastik olarak gerçekleşen şart yapısı, hareketi gerçekleştirmesi beklenen kişinin istek ve niyetini ifade eden bir şartı da anlatabilmektedir:

Bardl-geldi nağım gazıp, galanıñ içinden çıkaymakçı bolsalaram, şolarıñ çıkcak değişiğiniñ ağzında on-onbäşs sanı eli yalın yalı gılıçlı pıyadani goyarıs (Govşudov, 1990, s. 251). 'Eni sonu lağım kazıp, kalenin içinden çıkacak olsalar da, onların çıkacakları deliğin ağzına on onbeş tane eli yalın kılıçlı piyadeyi koyarız.'

\subsection{0. İsteğin Gerekliliğinin Şartı}

Şart çekiminde gelen bol- fiili ile perifrastik olarak gerçekleşen şart yapısı ile konuşurun, yapılması gereken işe olan bakış açısı, isteği anlatılmaktadır:

Övezmırat, sen hiç vă̆t ızıñ alada etmegin. Bilip bolmaz, göçüläymeli bolsa, göçüñi alıp gideris (Govşudov, 1990, s. 236). 'Övezmırat, sen arkanı hiç merak etme. Bilinmez, göç etmek gerekirse, eşyanı alıp gideriz.'

\section{SONUÇ}

Imek fiilinin hikâye, rivayet, şart çekimlerinin isimlerde olduğu gibi fiillerde de birleşik yapı kurduğu görüşü temelinde hikâye, rivayet ve şart birleşik çekimlerine göre oluşturulacak bir gramer yaklaşımı ile Türkmen Türkçesindeki bütün yapılanmalar değerlendirilebilmekte 
ve kipliklerin kullanımındaki zenginlik daha iyi ortaya konulmaktadır. Türkmen Türkçesi katmerli yapılar açısından oldukça zengindir. Kelimelerin temel anlamlarının ve yan anlamlarının olabildiği gibi, art zamanlı bir yaklaşımla, Türk dilinin eklerinin de temel fonsiyonu ve yardımcı fonksiyonları olabildiği açıktır. Eklerin adlandırılmasında eklerin asıl fonksiyonlarına göre terimlerin kullanılması gerekir. Ancak birçok çalışmada istek kipliği olarak ele alınan [-ası, -esi] ekinin Türkmen Türkçesinde aslında bir kip ekinden çok fiilimsi yapan bir ek olduğu görülür. Nitekim, iyelik ekleri ile değil de şahıs ekleri ile çekimlerinin yapılabilmesi kip eklerinin önemli bir ayırıcı özelliğidir. Bu sebeple bir kip eki olarak değerlendirilemezler. \{mAkçI\} ekinin Türkmen Türkçesindeki asıl fonksiyonu ise istek anlatmaktan çok bir niyet dile getirmedir ve Türkmen Türkçesinde fonksiyonuna uygun olarak adlandırılmıştır (Erdem, 2015, s. 61).

Ancak diğer yandan Baskakov'un 1970'te yayımlanan çalışmasındaki [-ayadı, -äyedi] ekinin doğrudan istek eki olarak kabul edilmesi geleneği, Türkmenistan'daki çalışmalarda günümüzde de sürdürülmüş ancak aynı dönemlerde Türkmen Dialektleriniñ Oçerki (1970) ve Türkmen Diliniñ Diyalektlerinde ve Gepleşiklerinde İşlikler (1988, s. 238) adlı çalışmalarda standart tür için gösterilen [ay, -ey] istek eki ile arasındaki ince fonksiyon farkı dikkate alınmamıştır. Türkmen Türkçesinde tek başına kullanım sıklığı düşük olsa bile, [-ay, -ey] ekinin kullanımı, anlam ve fonksiyonu ve [-ayadı, -äyedi] eki ile kullanım ve anlam farkı göz ardı edilemez:

\begin{tabular}{|c|c|}
\hline İstek & İsteğin Hikâyesi \\
\hline yazayın, yazayayın, işläyeyin & yaza:yadım, işlä:yedim \\
\hline yaza:y (yaza:), işlä:y & yaza:yadıñ, işlä:yediñ \\
\hline yaza:ysın, işlä:ysin & yaza:yadı, işlä:yedi \\
\hline yazalıñ, yazayalın, işläyeliñ & yaza:yadık, işlä:yedik \\
\hline 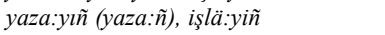 & yaza:yadıñz, işlä:yediñiz \\
\hline yaza:ysinlar (yaza:sınlar), işlä:ysinler & yaza:yadılar, işlä:yediler \\
\hline
\end{tabular}

Türkmen Türkçesinde istek kipi fonksiyonuna sahip olan asıl ek [-gay, -gey] > [-ay, -ey] ekidir ve hâlâ kullanımda olan bu şekildeki basit çekimi ile gramerlerde yer almalıdır. [-ay, -ey] istek ekinin temel fonksiyonu Türkmen Türkçesinde kaybolmamakla birlikte, kullanım ve fonksiyon genişliği kazanmıştır. Katmerli yapıların büyük oranda istek eki temelinde kurulduğu dikkati çekmekle birlikte konuşur açısından veya anlatılan hareketi gerçekleştiren açısından istek, yerine göre şart ve bazen da beklenti veya tasdik etme veya etmeme de ifade edebilmektedir. Bu durum Türkmen Türkçesinin gerek yazı dilinde gerekse konuşma dilinde açıkça görülmektedir. 


\begin{tabular}{cr} 
ÇÜTAD & Türkmen Türkçesinde İstek Eki Temelinde \\
Haziran 2019 & Kurulan Birleşik Kipler \\
\hline
\end{tabular}

\section{KORPUS}

Aşır, Ç. Göreş. Aşgabat.

Aşırov, Çarı (1988). Saylanan Eserleriñ İki Tomluğı. Aşgabat.

Baymıradov, A. (1986). Hayvanlar Hakındakı Türkmen Ertekileri. Aşgabat.

Deryayev, H. Ikbal. Aşgabat

Divangulıyev, H. (1992). Çuval Băğşı (Roman, edebî portretler). Aşgabat.

Durdıyev, A. (1982). Han Küyli. Aşgabat.

Govşudov, A. (1989). Perman. Aşgabat.

Govşudov, A. (1990). Mähri-Vepa. Aşgabat.

Hayidov, A. (1992). Uzın Ömrüñ Bir Güni. Aşgabat.

Hocageldiyev, N. (1974). Gülle Değen Sünbüller. Aşgabat.

Hudaynazarov, B. (1970). Gumlular. Aşgabat.

Kulıyev, G. (1971). Gara Kerven. Aşgabat.

Mämmedi(yev), Y. (1980, 1991). Şapak. Aşgabat.

Mıradov, S. (1987). Saygaklar. Aşgabat.

Nurmämmet, A. (1999). Oğuz Yurdu, Tarıhı Roman. Ankara.

Tağan, A. (1990). Sarağt Galast. Aşgabat.

Tağanov, Ş. (1992). Gara Yilgin. Aşgabat.

Tağanov, T. (1992). Mağtımgulı, Tarıhı Roman. Aşgabat.

Tüyliyev, O. (1990). Dordepel Povestler. Aşgabat.

\section{KAYNAKÇA}

Amansarıyev, C. (1970). Türkmen Diyalektologiyası. Aşgabat.

Ärnazarov, S. "Türkmen Türkçesinde Niyet Kipi ve Türkiye Türkçesinde Anlatımı", www.turkiyat.selcuk.edu.tr/pdf dergi/s13/arnazarov.pdf

Azimov, P. ve Sopıyev, G. ve Çönnäyev, Y. (1992). Türkmen Dili. Aşgabat. 
Azimov, P. - M. N. Hidırov, G. Sopıyev, C. Amansarıyev, G. Sarıyev, A. Ibrayımov (1960). Häzirki Zaman Türkmen Dili. Aşgabat.

Azimov, P. (1969). Türkmen Diliniñ Meseleleri. Aşgabat.

Baskakov, N. A. ve Hamzayev, M. Y. ve Çarıyarov B. (1970). Grammatika Türkmenskogo Yazıka I, Fonetika i Morfologiya. Aşhabat.

Baylıyev, S. (1992). Türkmen Diliniñ Tarıhı Grammatikası. Aşgabat.

Berdiyev, R. ve Kürenov, S. ve Şamıradov, K. ve Arazkulıyev, S. (1970). Türkmen Diliniñ Dialektleriniñ Oçerki. Aşgabat.

Berdiyev, R. (1988). Türkmen Diliniñ Dialektlerinde ve Gepleşiklerinde İşlikler. Aşgabat.

Borcakov, A. (1992). Türki Dilleriñ Günorta - Günbatar Toparında Işsliğiñ Buyruk Forması. Aşgabat.

Borcakov, A. ve Hocayev, B. (1980). Türki Dilleriñ GünortaGünbatar Toparında Arzuv ve Hökmanlık Añladyan İslik Formalart. Aşgabat.

Çarıyarov, B. (1969). Günorta-Günbatar Türki Dillerde İşlik Zamanları. Aşgabat.

Erdem, M. (2000). Türkmen Türkçesi Ağızlarında Olumlu Şimdiki Zaman Kullanımı. Bilig, 14/Yaz 2000, 55-73.

Erdem, M. (2008). Modern Oğuz Türkçesinde Belirsiz Geçmiş Zaman Ekleri. Türkiyat Araştırmalar Dergisi, Prof.Dr. M. Cihat Özönder'in Antsina 2, 5 (9), 199-215.

Erdem, M. (2015). Jelatelnoye nakloneniye v turkmenskom yazıke. Nauçnoye obozreniye sayano-altaya / Sayan-Altai Scientific Review, 2 (10), 57-63. (Türkmen Türkçesinde İstek Kipi)

Ergin, M. (2013). Edebiyat ve Eğitim Fakültelerinin Türk Dili ve Edebiyatı Bölümleri İçin Türk Dil Bilgisi. İstanbul.

Esenmedova, A. (2010). Häzirki Zaman Türkmen Dili (Morfologiya). Aşgabat.

Grunina, E. (2007). Türkmence açısından Türkçenin tarihi gramerinin bazı meseleleri üzerine. IV. Uluslararası Türk Dil Kurultayı Bildirileri I. Ankara, 681-684. 


$\begin{array}{cr}\text { ÇÜTAD } & \text { Türkmen Türkçesinde İstek Eki Temelinde } \\ \text { Haziran 2019 } & \text { Kurulan Birleşik Kipler }\end{array}$

Gurbanov, A. A. ve Kürräyev, N. ve Miradov, A. ve Pirliyev, G. (1989). Türkmen Dili. Așgabat.

Hamzayev, M. (1969). Türkmen Diliniñ Morfologiyasiniñ ve Sintaksisiniñ Meseleleri. Aşgabat.

Hıdırov, M. N. (1962). Türkmen Diliniñ Tarıhından Materyallar. Aşgabat.

Hocayev, B. (1978). Häzirki Zaman Türkmen Dilinde Isslik Formaları. Așgabat.

Hocayev, B. (1990). Türki Dilleriñ Günorta-Günbatar Toparında İsliğin Şert Forması. Aşgabat.

Mansuroğlu, M. (1958). Türkçede -gay, -gey Eki ve Türemeleri. Jean Deny Armağanı, Ankara, 171-183.

Nartıyev, N. (1994). Türkmen Dialektologiyasınıñ Esasları. Çarcev.

Söyegov, M. ve Sarıhanov, M. ve Borcakov, A. ve Hocayev, B. ve Ärnazarove, S. (2000/1999). Türkmen Diliniñ Grammatikasl: Morfologiya. Aşgabat.

Söyegov, M. ve Ärnazarov, S. (2017). Örnekli Türkmence Gramer: Türkmence Öğrenenler Için. Ankara / Aşkabat. 